Research Article

\title{
Electrochemical Determination of Hydrogen Entry to HSLA Steel during Pickling
}

\author{
Jari Aromaa (D), Antero Pehkonen, Sönke Schmachtel, Istvan Galfi, and Olof Forsén \\ Department of Chemical Engineering and Metallurgy, School of Chemical Technology, Aalto University, P.O. Box 16200, \\ Aalto 00076, Finland \\ Correspondence should be addressed to Jari Aromaa; jari.aromaa@aalto.fi
}

Received 3 November 2017; Accepted 23 January 2018; Published 7 March 2018

Academic Editor: Jun Liu

Copyright (c) 2018 Jari Aromaa et al. This is an open access article distributed under the Creative Commons Attribution License, which permits unrestricted use, distribution, and reproduction in any medium, provided the original work is properly cited.

Pickling with hydrochloric acid is a standard method to clean steel surfaces before hot-dip galvanizing. When normal low strength steels are pickled, hydrogen formed in pickling reactions does not have any significant harmful effect on the mechanical properties of steel. However, in pickling of steels with higher strength, the penetration of hydrogen into the steel may cause severe damages. The effect of pickling of high-strength low-alloy (HSLA) steels was investigated using a cell construction based on the DevanathanStachurski method with modified anodic surface treatment and hydrogen production using acid. The penetration and the permeability of hydrogen were measured using an electrochemical cell with hydrochloric acid on the one side of the steel sample and a solution of $\mathrm{NaOH}$ on the other side. No protective coating, for example, palladium on the anodic side of the sample, is needed. The penetration rate of hydrogen into the steel and exit rate from the steel were lower for higher strength steel.

\section{Introduction}

The number and the applications of new high-strength lowalloy (HSLA) steels with enhanced formability are constantly increasing. It is generally accepted that the transition from mild steel to HSLA steel occurs at yield strength of about $300 \mathrm{MPa}$. These steels have the potential to introduce weight savings while improving performance. Depending on design, the higher strength can evolve into better fatigue and crash performance, while maintaining or even reducing required material thickness [1]. However, HSLA steels may also give rise to some risks. For example, under certain circumstances, hydrogen introduced into steel during its manufacture, subsequent component fabrication, or in service may result in brittle failures at applied stresses far below the yield strength or the nominal design stress for the materials [2].

In this paper, we have studied hydrogen intrusion to HSLA steels during acid pickling to remove surface films before hot-dip galvanizing. The electrolytically produced hydrogen that penetrates into metal lattice can originate from corrosion, pickling, or electroplating [3]. In the pretreatment of the hot-dip galvanizing process, hydrogen may be absorbed in the steel during the pickling stage through contact with the hydrochloric acid which oxidizes the metal and forms adsorbed hydrogen that partly enters the metal lattice. After hot-dip galvanizing, the zinc layer prevents or delays the exit of the hydrogen from the steel [4]. Steels with tensile strength at the level of $800-1000 \mathrm{MPa}$ or higher are considered to be the most susceptible ones to hydrogen embrittlement $[5,6]$. The majority of steels have generally tensile strength in the range of $200-450 \mathrm{MPa}$, and they are apparently not subject to hydrogen embrittlement problems. Special consideration must be given to high strength steels, if they are required to be pickled [3].

Inhibitors are used to prevent pitting of steel surface in case of overpickling. They also minimize the dissolution of iron, decrease the acid consumption, and lower the formation of harmful fumes. Normally, inhibitors provide good protection against hydrogen absorption during acid cleaning. It is known that inhibitors such as benzotriazole obstruct or decrease the diffusion of atomic hydrogen into the steel. In addition, some nitrogen bearing organic compounds such as imidazoline have been found to be highly effective inhibitors of hydrogen penetration into low carbon steels $[2,7]$. 


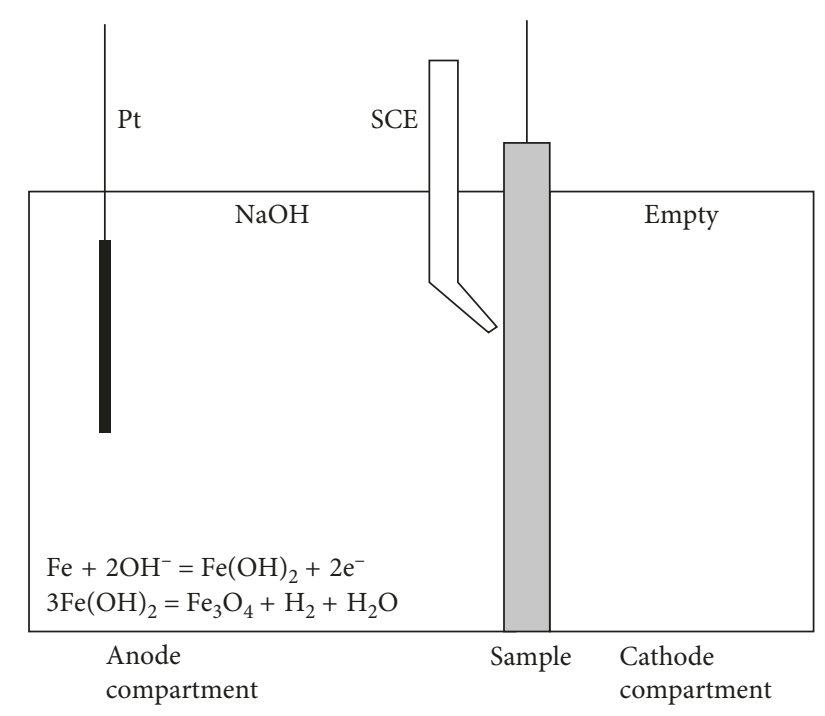

(a)

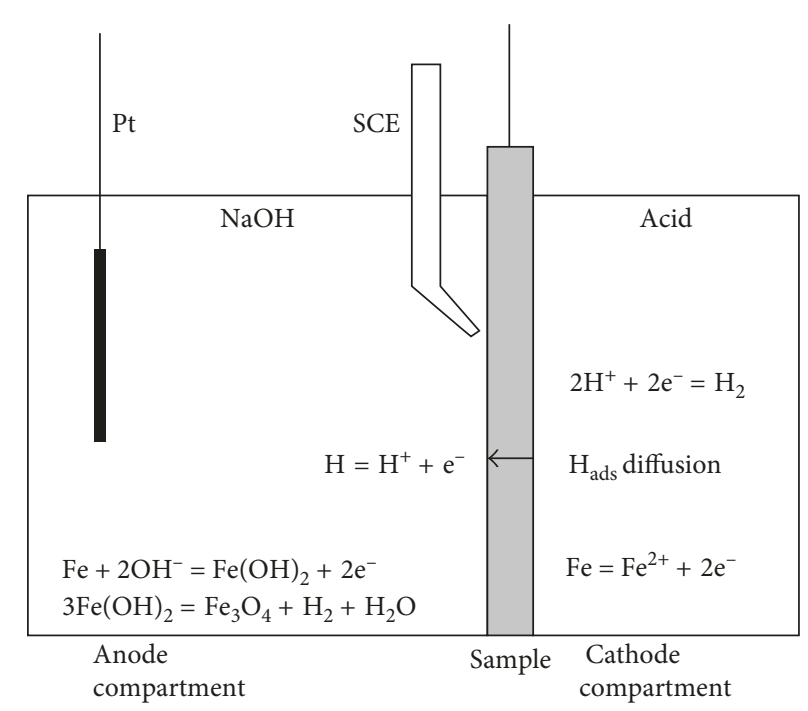

(b)

FIGURE 1: Schematic setup of the test cell with anodic and cathodic reactions at passivation and permeation test stages. Pt is platinum counterelectrode, and SCE is saturated calomel reference electrode. (a) During passivation. (b) During testing.

The Devanathan-Stachurski method is the most frequently utilized technique to measure the hydrogen permeation in metals. Hydrogen is produced on the cathodic side of the double cell using cathodic polarisation. Part of this hydrogen diffuses through the sample, and on the anodic side exiting hydrogen atoms are oxidized by applying an anodic current. Thickness of steel samples in hydrogen permeation experiment is typically $0.3-1.0 \mathrm{~mm}$. Galvanostatic current to produce hydrogen has varied from 0.05 to $100 \mathrm{~mA} / \mathrm{cm}^{2}$ [8-10]. The aim of this investigation was to measure the permeation of hydrogen through HSLA steels using the Devanathan-Stachurski method with modified anodic surface treatment and hydrogen production using acid. The permeation is commonly studied using external polarisation to produce the hydrogen, but we used the pickling acid as the hydrogen source. The samples had no Pd coating on the exit surface, but the exit surface was passivated potentiostatically using $\mathrm{NaOH}$ before permeation measurements. Passivation was done to produce a steady background current on the steel. A schematic diagram on the reactions and phenomena during the measurements is shown in Figure 1. In the anodic compartment, steel is first dissolved and passivated at a constant potential. The cathodic compartment is empty during the passivation stage. During the permeation tests in the cathodic compartment, steel is corroded by acid at the free corrosion potential, and part of the produced hydrogen enters the steel diffusing to the exit surface in the anode compartment. When hydrogen diffuses through the steel, hydrogen evolution begins on the anodic surface and this is detected as current increase.

Usually the anodic side of the steel sample is coated with palladium to ensure a uniform surface and to minimize the anodic dissolution of the metal during permeation current measurements. Palladium film favours the kinetics of hydrogen oxidation. Without Pd layer, the oxidation of hydrogen atoms could be incomplete due to the presence of an oxide film that could build up on a metal sample when anodically polarised in an alkaline medium. The oxide film acts as a barrier against hydrogen release. According to Manolatos et al. [11], without a palladium coating on the exit side of the sample the surface phenomena are not controlling and the passive layer on the exit side changes with time preventing stabilization of the hydrogen concentration on the exit side, and therefore stationary conditions cannot be obtained. This is the reason why most of the investigations have been carried out using palladium coating. The variation in hydrogen concentration is observed as the nonsteady state of the charging current curve. However, it is possible to obtain reproducible results by controlling the parameters related to the formation of the passive layer [11]. Our approach was to use long passivation times and subtract the steady passive current from hydrogen oxidation transient currents.

The charging of steel with hydrogen is usually done electrolytically or in hydrogen-containing atmosphere (cf. [12]), and the gaseous charging and electrolytic charging are considered equivalent. Identical setup with freely corroding charging side has been used, for example, in [13] to study the effect of pickling inhibitors for hydrochloric acid and in $[14,15]$ to study corrosion of pipeline steels. In [13], the effect of inhibitors on hydrogen permeation was calculated by comparing permeation current with and without inhibitor. In [14], the permeation current was used to evaluate the effect of additives and corrosion films on hydrogen absorption. In [15], the permeation current increased when the $\mathrm{H}_{2} \mathrm{~S}$ concentration in hydrogen entry environment increased. These examples indicate that use of freely corroding surface can be used to charge steel with hydrogen. In our work, the permeation of hydrogen was investigated using 1-4 mm thick steel samples, and several analysis methods were applied for estimating the diffusion coefficients. 


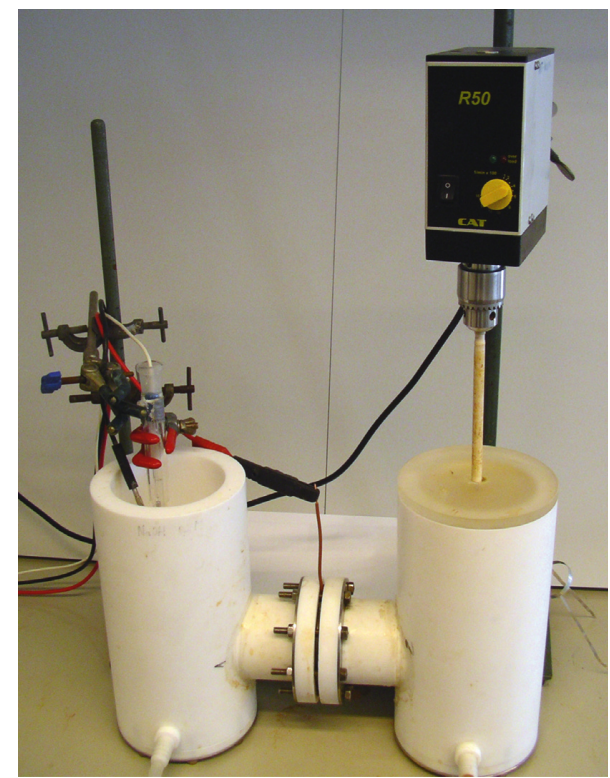

FIGURE 2: Test cell for permeation experiments, with compartment with pickling solution on the right side and $0.2 \mathrm{M} \mathrm{NaOH}$ on the left side.

TABLE 1: Chemical compositions of steels used in experiments.

\begin{tabular}{lccccccc}
\hline Steel grade & $C_{\max }$ & $\mathrm{Si}_{\max }$ & $\mathrm{Mn}_{\max }$ & $P_{\max }$ & $S_{\max }$ & $\mathrm{Al}_{\min }$ & $\mathrm{CEV}_{\max }$ \\
\hline S355 & 0.12 & 0.50 & 1.50 & 0.025 & 0.020 & 0.015 & 0.39 \\
S500 & 0.12 & 0.50 & 1.70 & 0.025 & 0.015 & 0.015 & 0.43 \\
S700 & 0.12 & 0.60 & 2.10 & 0.025 & 0.015 & 0.015 & 0.41 \\
S900 & 0.20 & 0.60 & 2.20 & 0.025 & 0.010 & 0.015 & 0.57 \\
S235 & 0.17 & - & 1.40 & 0.035 & 0.035 & - & 0.35 \\
\hline
\end{tabular}

\section{Experimental}

A double-compartment test cell was constructed to measure the permeation of hydrogen through steel (Figure 2). Material of this double cell was Teflon, and the steel sample was installed between the two separate cells. The electrochemical tests were done using Autolab PGSTAT30 Potentiostat with Autolab Software 4.9.

Test materials were high-strength low-alloy (HSLA) steels with yield strength of 355, 500, 700, and $900 \mathrm{MPa}$. Samples for experiments were cut from rectangular hollow sections $50 \mathrm{~mm}$ wide with $6 \mathrm{~mm}$ material thickness. The material in these hollow sections is hardened, hot-rolled steel, and corresponding grade carbon steel S235 was used as a reference material. The tensile strength of this steel is $235 \mathrm{MPa}$. Chemical compositions of test materials are shown in Table 1. CEV (carbon equivalent for estimation of steel weldability) values calculated using $\mathrm{CEV}=\mathrm{C}+\mathrm{Mn} / 6+(\mathrm{Cr}+\mathrm{Mo}+\mathrm{V}) / 5+(\mathrm{Ni}+\mathrm{Cu}) / 15$ were taken for small material thicknesses used in this study. The analyses and material properties were supplied by the manufacturer and referred to general product qualities.

The surface area of the sample that was in contact with solution was $19.6 \mathrm{~cm}^{2}$. The thickness of the sample area exposed to the solutions was reduced by turning (Figure 3). The thickness of exposed sample area varied from 1 to $4 \mathrm{~mm}$.

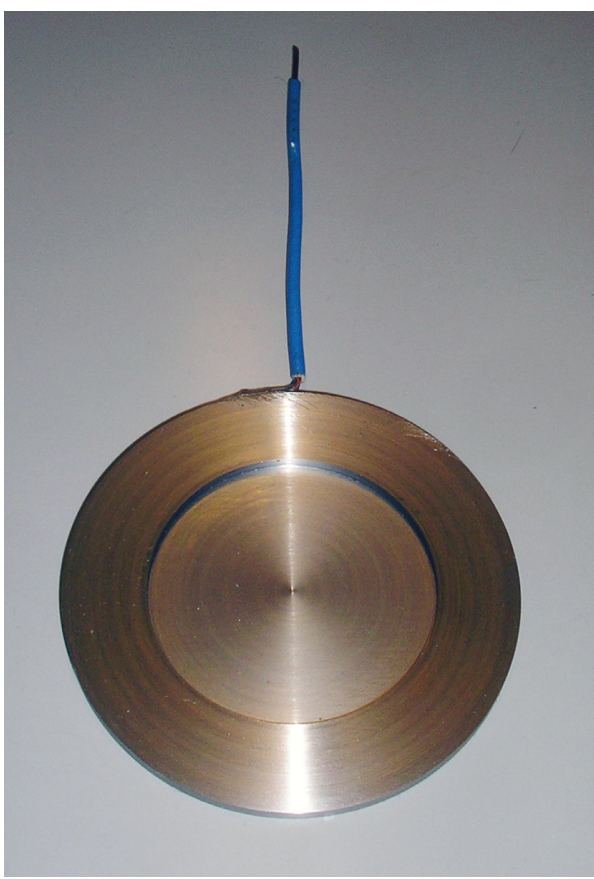

Figure 3: Test sample after turning. The middle part is for hydrogen permeation and the machined side was in the hydrogen evolving side.

After thickness adjustment, the anodic surface of the sample was ground with emery paper (grade 400) followed by washing in citric acid just before electrochemical experiments. No coating was used on the anodic side of the sample.

The anodic potential in potentiostatic permeation experiments was determined by potentiodynamic polarisation measurements for carbon steel S235 and S700 in $0.2 \mathrm{M}$ $\mathrm{NaOH}$ solution at room temperature. Anodic polarisation curve from the open circuit was measured with a potential sweep rate $100 \mathrm{mV} / \mathrm{min}$.

Hydrochloric acid diluted to $16.5 \%(5.4 \mathrm{M})$ was used in the permeation measurements to produce hydrogen on steel surface. The acid was used both without dissolved iron and with $\mathrm{Fe}^{2+}$ concentrations $14 \mathrm{~g} / \mathrm{L}(0.25 \mathrm{M})$ and $45 \mathrm{~g} / \mathrm{L}(0.8 \mathrm{M})$ to simulate a used pickling bath. Iron was added as $\mathrm{FeCl}_{2} \cdot 4 \mathrm{H}_{2} \mathrm{O}$. Temperature of the solution was $20^{\circ} \mathrm{C}$. The sample was installed between the two compartments of the cell, and $1 \mathrm{~L}$ of $0.2 \mathrm{M} \mathrm{NaOH}$ solution was added into the anodic side of the test cell. Thereafter, sample was polarised to a potential of $0 \mathrm{mV}$ versus SCE to form a passive layer on the surface, and the current was measured up to steady state situation (about $15 \mathrm{~h}$ ). The passive film in alkaline solution is usually magnetite $[16,17]$. The passivation procedure causes initially an increase in the current due to the corrosion of the steel when the oxide layer is formed, and this current decreases with time as the passive film reaches a steady state. In the passive state, steel dissolves, but at a low and constant rate. When the passive film had reached a steady state, hydrochloric acid $(1 \mathrm{~L})$ was introduced in the cathodic compartment. When hydrogen started to diffuse to the exit side a current increase was seen. When the current reached 


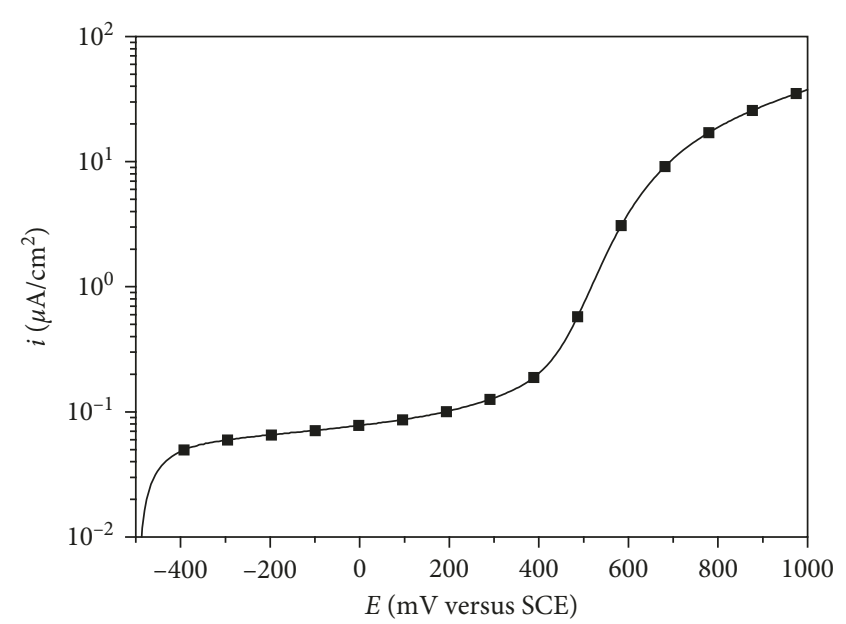

Figure 4: The polarisation curve of carbon steel S253 in $0.2 \mathrm{M}$ $\mathrm{NaOH}$ at $20^{\circ} \mathrm{C}$.

a steady maximum level, the acid was removed through the bottom valve, and after some time, a decrease of the anodic current was observed. During the whole measurement, the anodic side of the sample was kept at constant potential. In the beginning of the test, the current was due to anodic oxidation and passivation of steel. Oxidation of hydrogen that had diffused to exit side was seen as current increase. When hydrogen was stopped by removing the acid, current started to decrease and reached finally the same passive current level as before the introduction of acid. This background current is subtracted from the current measured during the permeation measurements. Thus, the effect of only hydrogen diffusion on the current could be observed.

To increase the uptake of hydrogen into the metal, recombination poisons such as arsenic, hydrogen sulphide, and thiourea can be used [18]. These elements block adsorption sites on electrode surface diminishing the coverage by adsorbed hydrogen. The adsorbed $\mathrm{H}$ is an intermediate resulting from discharge of $\mathrm{H}^{+}$, and its recombination produces $\mathrm{H}_{2}$ in the cathodic hydrogen evolution. No tests were done with hydrogen poisons as they are not used in pickling baths. The use of recombination poisons was not found to be necessary as detectable amount of hydrogen was generated from the concentrated hydrogen chloride solutions used in this work.

\section{Results and Discussion}

The open circuit potential of carbon steel S253 was $-490 \mathrm{mV}$ versus SCE and a wide passive range up to the potential of $+400 \mathrm{mV}$ versus SCE was found in $0.2 \mathrm{M} \mathrm{NaOH}$ solution (Figure 4). Based on these results, the potential of $0 \mathrm{mV}$ versus SCE was chosen for the permeation measurements. The selected potential is on the passive range of tested steels, and it is higher than the equilibrium potential of $\mathrm{H}^{+} / \mathrm{H}_{2}$ reaction so oxidation of diffused hydrogen was guaranteed. The current density at this potential is less than $0.1 \mu \mathrm{A} / \mathrm{cm}^{2}$. The dissolution rate of steel is at very low level, approximately $1 \mu \mathrm{m} /$ year.

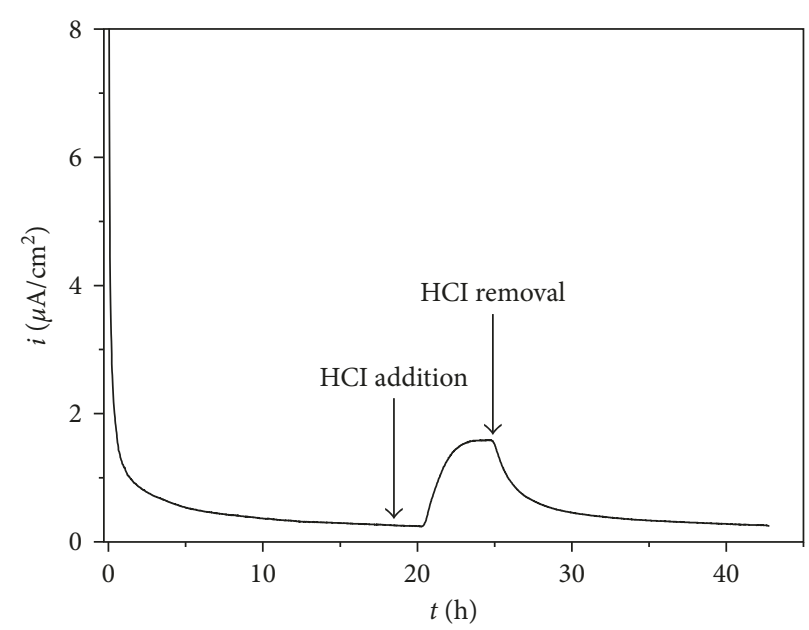

FIgURe 5: A typical current density versus time curve measurement in passivation and permeation experiment in $16.5 \% \mathrm{HCl}$ for steel S355.

A typical current density versus time curve in an experiment on steel S355 is shown in Figure 5. The current is related only to the reaction rates on the steel surface in the anodic compartment containing $\mathrm{NaOH}$. A high current density is observed at the beginning of the experiment, when the steel surface is still in active state, and much lower current density of about $0.3 \mu \mathrm{A} / \mathrm{cm}^{2}$ was reached when the steel passivates. Hydrochloric acid was added on the cathodic side of the cell after $18 \mathrm{~h}$ when the anodic surface had reached the passive state. After a delay of over two hours, an increase in the current was seen in the anodic compartment. This current increase is due to hydrogen that had diffused through the steel and was oxidized on the anodic side. A steady maximum was observed after about $5 \mathrm{~h}$ from the acid addition indicating steady flux of hydrogen through the steel sample. At this point, the hydrochloric acid was removed from the cathodic side of the cell. The anodic current density started to decrease as no more hydrogen was produced on the acid side, and hydrogen charged into the steel was consumed. At the end of the test, the current was approximately same passive current as before acid addition.

Results for hydrogen permeation experiments for high strength steel are shown in Figure 6. The curves show only the part after adding $\mathrm{HCl}$ in the cathodic compartment. The hydrogen penetration time through the sample is similar for all steels with similar thickness, as shown in Figure 6. This is seen as an increase in the current density after $\mathrm{HCl}$ addition. The maximum current density is lowest for the steel $\mathbf{S 9 0 0}$ and highest for steel S500. The grade of the steel does not have direct correlation with the maximum current. The maximum current density gives the maximum penetration rate of hydrogen through the steel. Theoretically, integration of current versus time curve gives the amount of hydrogen penetrated through the sample.

Introduction of iron into the pickling acid has only a minor effect on the current versus time curve (Figure 7). As an example, the influence of ferrous ion concentrations $0 \mathrm{~g} / \mathrm{L}, 14 \mathrm{~g} / \mathrm{L}$, and $45 \mathrm{~g} / \mathrm{L}$ on hydrogen entry for $\mathrm{S} 700$ steel is 


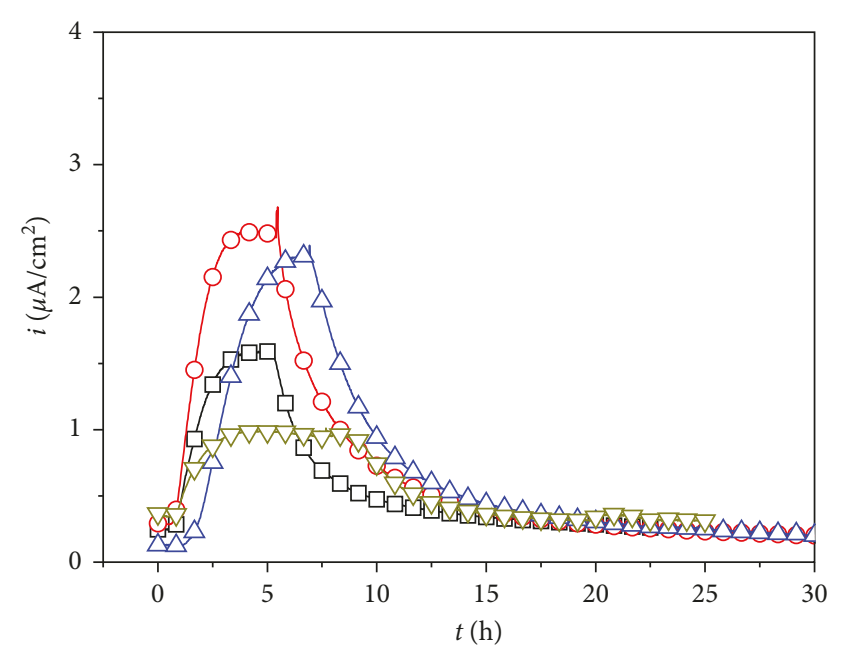

Steel grade

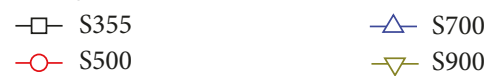

Figure 6: Permeation of hydrogen in $16.5 \% \mathrm{HCl}$ for different steel grades with sample thickness $1 \mathrm{~mm}$.

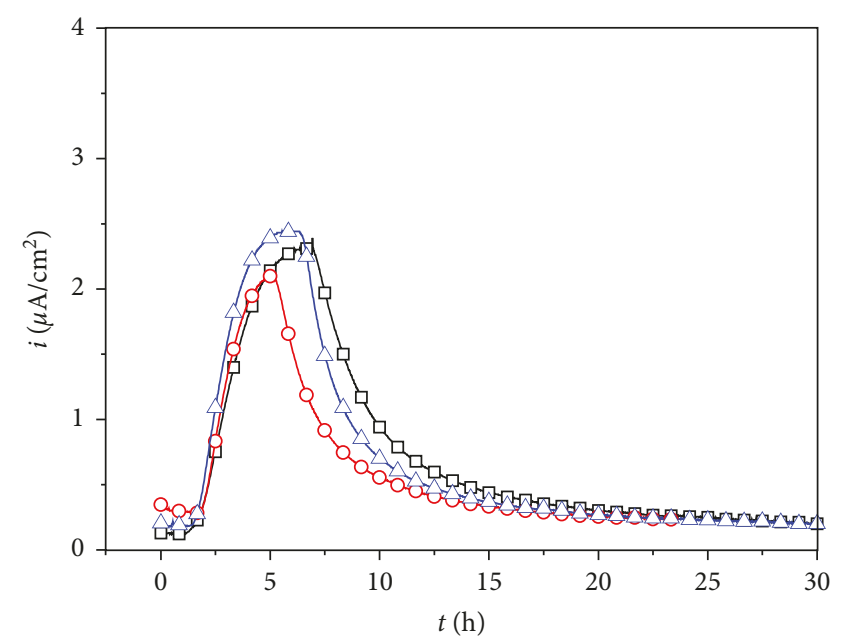

Iron concentration

$\rightarrow-0 \mathrm{~g} / \mathrm{L}$

$-14 \mathrm{~g} / \mathrm{L}$

$\neg-45 \mathrm{~g} / \mathrm{L}$

FIgURE 7: The influence of iron content of the $\mathrm{HCl}$ on the permeation in steel S700.

shown in Figure 7. Dissolved iron had only a minor effect on the permeation of hydrogen in the studied steels.

The hydrogen diffusion coefficient was calculated by using four different methods given in $[19,20]$ :

(1) The time lag method

(2) Breakthrough time

(3) Half-rise time

(4) Analysis of the beginning decay transient

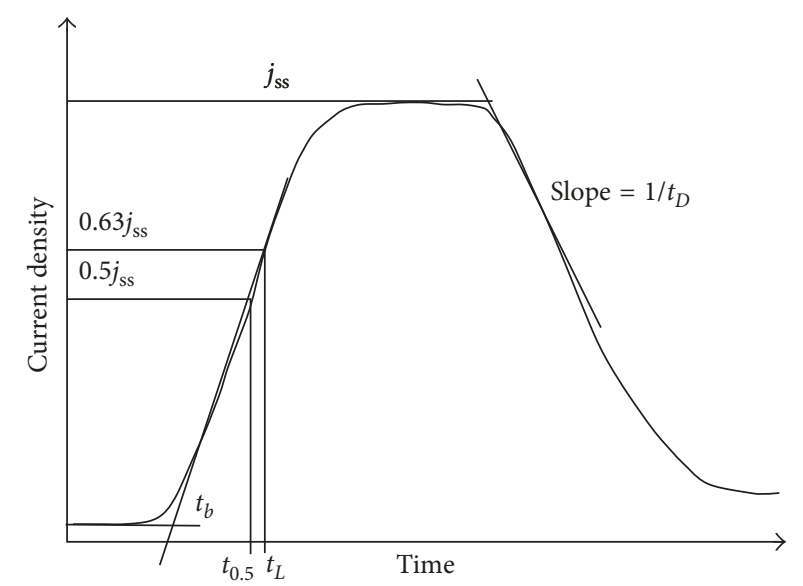

FIGURE 8: Determination of characteristic times for calculation of diffusion coefficients: time lag $t_{D}$, breakthrough time $t_{b}$, half-rise time $t_{0.5}$, and decay time constant $t_{D}$.

The analysis methods are based on the solution of the diffusion equation with constant concentration boundary conditions. The solution for the charging transient, derived by separation of variables, is shown in the following equation:

$$
I=n F A D \frac{c_{1}}{L}\left[1+2 \sum_{n=1}^{\infty}(-1)^{n} \exp \left(\frac{-D n^{2} \pi^{2} t}{L^{2}}\right)\right],
$$

and for the decay transient (both ends at zero concentration and linear initial condition), the following solution is obtained:

$$
I=n F A D \frac{c_{1}}{L} 2 \sum_{n=1}^{\infty}(-1)^{n+1} \exp \left(\frac{-D n^{2} \pi^{2} t}{L^{2}}\right) .
$$

Figure 8 shows the principles for determination of characteristic times for calculation of diffusion coefficients.

In the time lag method, analysis is done by integrating the rising curve to calculate the quantity of hydrogen, which has permeated through the sample as a function of time. An extrapolation of the plot of quantity against time gives the time lag $t_{L}$ which is related to the diffusion constant by

$$
D_{L}=\frac{1}{6} \cdot \frac{L^{2}}{\pi^{2} \cdot t_{L}}
$$

The $t_{L}$ in (3) can be obtained by determining the time at which the rate of permeation is 0.63 times the steady-state value described by current density $j_{\mathrm{ss}}[19]$.

In the breakthrough time method, the time $t_{b}$ is obtained by drawing tangent in the rising part of the curve. The tangent crosses the time axis at point $t_{b}[19]$ :

$$
D_{B}=0.5 \cdot \frac{L^{2}}{\pi^{2} \cdot t_{b}}
$$

In the half-rise time method, the characteristic time $t_{0.5}$ corresponds to the current density that is 0.5 times the current density at steady-state situation $j_{\text {ss. }}$. Diffusion coefficient can then be calculated as follows [19]: 
TABle 2: Average values of diffusion coefficients $\left(\mathrm{cm}^{2} / \mathrm{s}\right)$ for test materials calculated using the four methods.

\begin{tabular}{lcccc}
\hline Method/steel & $355 \mathrm{MPa}$ & $500 \mathrm{MPa}$ & $700 \mathrm{MPa}$ & $900 \mathrm{MPa}$ \\
\hline$D_{0.5}$ & $1.82 \cdot 10^{-7}$ & $1.6 \cdot 10^{-7}$ & $1.61 \cdot 10^{-7}$ & $2.5 \cdot 10^{-7}$ \\
$D_{L}$ & $1.16 \cdot 10^{-7}$ & $8.78 \cdot 10^{-8}$ & $3.2 \cdot 10^{-8}$ & $2.54 \cdot 10^{-8}$ \\
$D_{B}$ & $1.96 \cdot 10^{-7}$ & $1.49 \cdot 10^{-7}$ & $1.73 \cdot 10^{-7}$ & $1.93 \cdot 10^{-7}$ \\
$D_{D}$ & $1.76 \cdot 10^{-7}$ & $1.81 \cdot 10^{-7}$ & $9.76 \cdot 10^{-8}$ & $1.26 \cdot 10^{-7}$ \\
\hline
\end{tabular}

$$
D_{0.5}=0.138 \cdot \frac{L^{2}}{t_{0.5}}
$$

In the decay transient analysis, a characteristic time constant $t_{D}$ is determined using the slope of current decay after the steady state. The obtained current versus time is corrected for offsets and divided by its maximum value at the steady state. Taking the logarithm of the obtained normalized current, one obtains for the beginning decay transient a linear section from which the slope is the inverse decay time constant [20]:

$$
D_{D}=\frac{1}{t_{D}} \frac{L^{2}}{\pi^{2}}
$$

When the sample thickness increases, the diffusion coefficient value in replicate tests seems to become more reproducible. At sample thicknesses of $1 \mathrm{~mm}$, the diffusion coefficient values were from $10^{-9}$ to $10^{-6} \mathrm{~cm}^{2} / \mathrm{s}$. When the sample thickness was $1.5-2 \mathrm{~mm}$, the range was from $10^{-8}$ to $10^{-6} \mathrm{~cm}^{2} / \mathrm{s}$ and with sample thicknesses of $4 \mathrm{~mm}$ from $10^{-7}$ to $10^{-6} \mathrm{~cm}^{2} / \mathrm{s}$. This effect was clearer with $500 \mathrm{MPa}$ and $700 \mathrm{MPa}$ samples. This effect agrees with the finding of Charca et al. [21] by using Armco iron. It is generally easier to attain solubility limits with thinner metallic samples than thicker ones, which contain more material defects and hence trapping sites.

The diffusion coefficient was not dependent on the analysis method. The coefficient decreased slightly with increasing strength. The results presented in Table 2 show that both charging and discharging transients have similar diffusion coefficients. This is important for the argumentation, whether deep traps are significantly involved and filled during the charging.

Filling of traps would lead to an internal accumulation of hydrogen, and this hydrogen cannot be detected in the charging transient anymore. Since deep traps are preferentially filled before the hydrogen can diffuse on, the penetration of the hydrogen is delayed, which would show up in the analysis as changed diffusion coefficients. For the decay transient, when all the deep traps were already filled, the diffusion of the hydrogen would proceed normally. Thus, whenever there would be deep traps present, this should be visible as a significant difference in the diffusion coefficient determination methods for charging (3-5) compared to the discharge method (6). That the diffusion coefficients obtained from the decay transient are similar to the other method shows, thus, that an involvement of traps for the tested steels can be neglected. That iron-based samples do not have a significant number of traps has been already mentioned in [22].
To evaluate a concrete problem case, the here obtained diffusion coefficients can be used to simulate the penetration of hydrogen during pickling and the release of it during the time between pickling and hot dip galvanizing. This, however, is very much depending on the dimensions of the steel product and on the degree of deformation within that product. All this we leave for future investigations.

\section{Conclusions}

The purpose of this paper was to study the intrusion of hydrogen during pickling of steel. Hydrogen permeation can be caused by pickling acid, such as $\mathrm{HCl}$, instead of cathodic hydrogen production that is mainly used in investigations found in the literature.

No protective coating, for example, palladium on the anodic side of the sample, is required. Permeation measurement needs to be carried out after passivation of steel, and this low background current is to be subtracted from the measured current before the calculation of the diffusion coefficient.

The permeation rate of hydrogen into the steel and desorption rate from the steel are slightly lower for higher strength steel. This means that if these steels are plated soon after pickling, for example in hot-dip galvanizing, hydrogen has no time to leave steel and hydrogen-induced failures may occur.

Iron dissolved in pickling acid has no essential effect on the permeation of hydrogen.

\section{Conflicts of Interest}

The authors declare that they have no conflicts of interest.

\section{References}

[1] D. Schaeffler, "Introduction to advanced high-strength steels-Part I," Stamping Journal, vol. 16, pp. 22-28, 2004.

[2] T. P. Groeneveld, E. E. Fletcher, and A. R. Elsea, "A study of hydrogen embrittlement of various alloys, National Aeronautics and Space Administration Report,"Annual Summary Report, p. 40, NASA, Washington, DC, USA, 1966, https://ntrs. nasa.gov/archive/nasa/casi.ntrs.nasa.gov/19660025404.pdf.

[3] AZoM, Galvanised Steel-Embrittlement Due to Hot Dip Galvanising, AZoM, Sydney, Australia, 2002, https://www. azom.com/article.aspx?ArticleID=1407.

[4] A. El Hajjami, M. Gigandet, M. De Petris-Wery et al., "Hydrogen permeation inhibition by zinc-nickel alloy plating on steel XC68," Applied Surface Science, vol. 255, no. 5, pp. 1654-1660, 2008.

[5] E. Hörnlund, J. K. T. Fossen, S. Hauger, C. Haugen, T. Havn, and T. Hemmingsen, "Hydrogen diffusivities and concentrations in $520 \mathrm{M}$ carbon steel under cathodic protection in $0.5 \mathrm{M} \mathrm{NaCl}$ and the effect of added sulphite, dithionite, thiosulphate, and sulphide," International Journal of Electrochemical Science, vol. 2, pp. 82-92, 2007.

[6] J. Ćwiek and K. Nikiforov, "Hydrogen degradation of highstrength weldable steels in seawater," Materials Science, vol. 40, no. 6, pp. 831-835, 2004.

[7] N. Amokrane, C. Gabrielli, G. Maurin, and L. Mirkova, "Effect of organic additives on hydrogen permeation into an iron 
membrane studied by frequency analysis techniques," Electrochimica Acta, vol. 53, no. 4, pp. 1962-1978, 2007.

[8] J. O'M Bockris and P. K. Subramanyan, "Hydrogen embrittlement and hydrogen traps," Journal of the Electrochemical Society, vol. 118, no. 7, pp. 1114-1119, 1971.

[9] R.-H. Sang, S. Pyun Il, and R. A. Oriani, "Hydrogen permeation through the passivation film on iron by time-lag method," Journal of the Electrochemical Society, vol. 137, no. 6, pp. 1703-1706, 1990.

[10] M. A. V. Devanathan and Z. Stachurski, "The adsorption and diffusion of electrolytic hydrogen in palladium," Proceedings of the Royal Society London, Series A Mathematical and Physical Sciences, vol. 270, no. 1240, pp. 90-102, 1962.

[11] P. Manolatos, M. Jerome, C. Duret-Thuali, and J. Le Coze, "The electrochemical permeation of hydrogen in steels without palladium coating. Part I: interpretation difficulties," Corrosion Science, vol. 37, no. 11, pp. 1773-1783, 1995.

[12] Q. Liu and A. Atrens, "A critical review of the influence of hydrogen on the mechanical properties of medium-strength steels," Corrosion Reviews, vol. 31, no. 3-6, pp. 85-103, 2013.

[13] B. Ramesh Babu and R. Holze, "Corrosion and hydrogen permeation inhibition for mild steel in $\mathrm{HCl}$ by isomers of organic compounds," British Corrosion Journal, vol. 35, no. 3, pp. 204-209, 2000.

[14] Y. Cheng, L. Yang, and F. King, "Analysis of hydrogen permeation through pipeline steel in near-neutral $\mathrm{pH}$ SCC environments," in Proceedings of 2000 International Pipeline Conference, vol. 2, pp. 1479-1485, Alberta, Canada, October 2000.

[15] J. Yang, L. Zhang, L. Xu, and M. Lu, "Influence of $\mathrm{H}_{2} \mathrm{~S}$ and $\mathrm{CO}_{2}$ corrosion scales on hydrogen permeation in X65 steel," Corrosion, vol. 08412, p. 8, 2008.

[16] R. O. Rihan and S. Nesic, "Erosion-corrosion of mild steel in hot caustic. Part I: NaOH solution," Corrosion Science, vol. 48, no. 9, pp. 2633-2659, 2006.

[17] T. D. Burleigh, P. Schmuki, and S. Virtanen, "Properties of the nanoporous anodic oxide electrochemically grown on steel in hot $50 \% \mathrm{NaOH}$," Journal of the Electrochemical Society, vol. 156, pp. C45-C53, 2009.

[18] S. Y. Qian, B. E. Conway, and G. Jerkiewicz, "Kinetic rationalization of catalyst poison effects on cathodic $\mathrm{H}$ sorption into metals: relation of enhancement and inhibition to H coverage," Journal of the Chemical Society, Faraday Transactions, vol. 94, no. 19, pp. 2945-2954, 1998.

[19] B. S. Chaudhari and T. P. Radhakrishnan, "Boundary conditions during the electropermeation of hydrogen through pure iron," Corrosion Science, vol. 30, no. 12, pp. 1219-1234, 1990.

[20] J. O’M Bockris and M. A. V. Devanathan, "The determination of the coverage on nickel and steel during electrolytic hydrogen evolution," Tech. Rep. 4, Contract No. 551(22) NR036028, Office of Naval Research, p. 41, Arlington, VL, USA, 1961, http://www.dtic.mil/docs/citations/AD0254474.

[21] S. Charca, O. Uwakweh, B. Shafiq, and V. Agarwala, "Characterization of hydrogen permeation in armco-fe during cathodic polarization in aqueous electrolytic media," Journal of Materials Engineering and Performance, vol. 17, no. 1, pp. 127-133, 2008.

[22] C. Gabrielli, G. Maurin, L. Mirkova, H. Perrot, and B. Tribollet, "Transfer function analysis of hydrogen permeation through a metallic membrane in a Devanathan cell. I. Theory," Journal of Electroanalytical Chemistry, vol. 590, no. 1, pp. 1-14, 2006. 


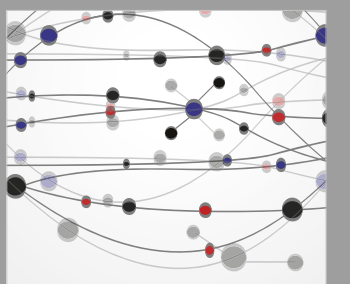

The Scientific World Journal
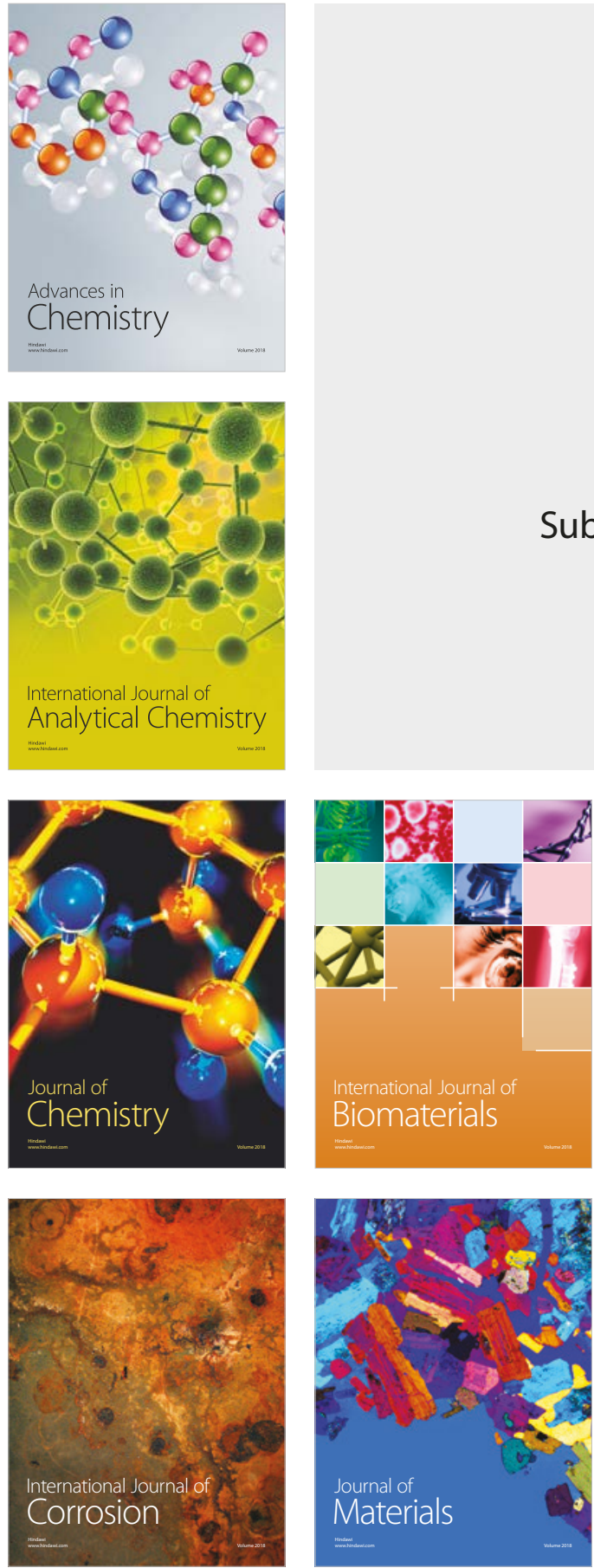

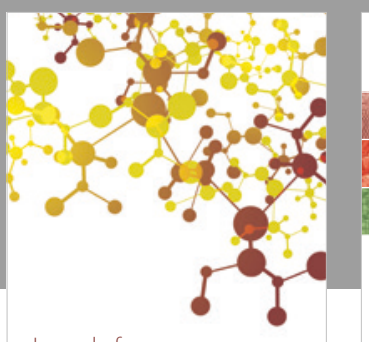

Journal of

Applied Chemistry
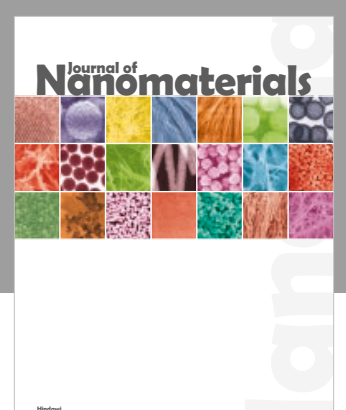

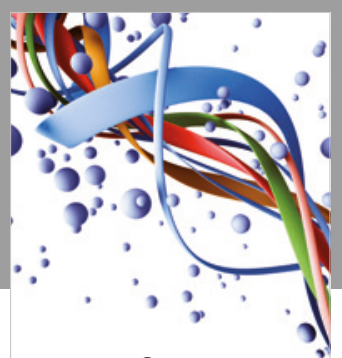

Scientifica

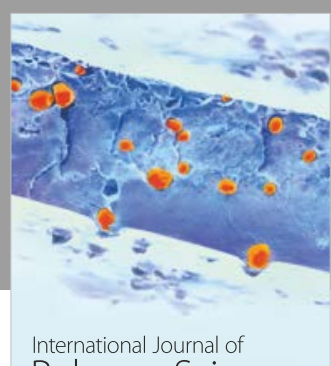

Polymer Science

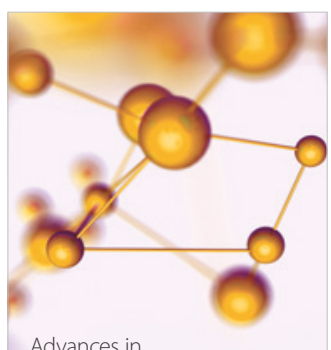

Physical Chemistry
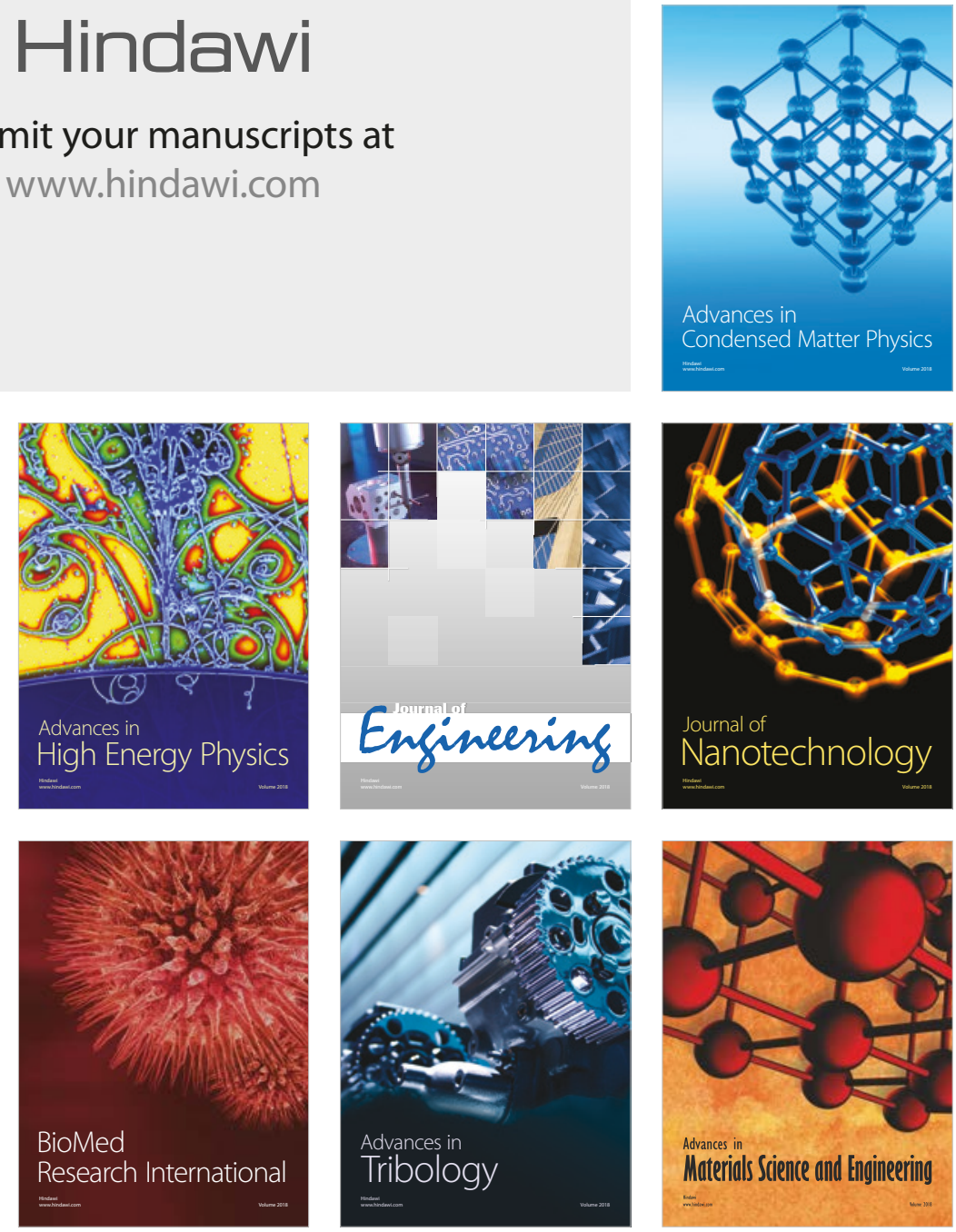